\title{
Health-related quality of life and body mass index among US adolescents
}

\author{
Wanjun Cui, \\ Division of Population Health, Centers for Disease Control and Prevention, 4770 Buford Highway, \\ NE, MS F-78, Atlanta, GA 30341, USA \\ Matthew M. Zack, and \\ Division of Population Health, Centers for Disease Control and Prevention, 4770 Buford Highway, \\ NE, MS F-78, Atlanta, GA 30341, USA

\section{Holly Wethington} \\ Division of Nutrition, Physical Activity, and Obesity, National Center for Chronic Disease \\ Prevention and Health Promotion, Centers for Disease Control and Prevention, Atlanta, GA, USA \\ Wanjun Cui: wtd9@cdc.gov
}

\section{Abstract}

Purpose-To examine the magnitude of differences in health-related quality of life (HRQOL) by body mass index (BMI) in a population-based sample of United States adolescents overall and by sex, and to provide national prevalence estimates of reported HRQOL outcomes for not only obese and overweight but also underweight adolescents.

\begin{abstract}
Methods-From the 2001 through 2010 cross-sectional National Health and Nutrition Examination Surveys, we estimated the percentages of four HRQOL outcomes-self-rated health, physically unhealthy days, mentally unhealthy days, and activity limitation days-in four BMI categories—obese, overweight, normal weight, and underweight—of approximately 6,000 US adolescents aged 12-17 years. We also estimated the percentages for boys and girls separately.

Results-Substantial gaps in self-rated health exist between normal-weight adolescents and those who are obese and overweight, but not underweight. Eighteen percent (95\% CI 15-22) of obese adolescents reported fair or poor health compared to only $5 \%$ (95\% CI 4-7) of normalweight adolescents. Thirty-seven percent (95\% CI 33-42) of obese adolescents reported excellent or very good health, compared to $65 \%$ (94\% CI 63-67) of normal-weight adolescents. However, all BMI groups reported similar percentages of physically unhealthy days, mentally unhealthy days, and activity limitation days. The associations between HRQOL and BMI groups did not vary by sex. Boys generally reported significantly better self-rated health and mental health than girls. Specifically, obese boys reported better self-rated health, mental health, and fewer activity limitation days than obese girls.
\end{abstract}

Correspondence to: Wanjun Cui, wt d9@cdc.gov.

Conflict of interest The authors report no conflict of interest.

Disclaimer: The findings and conclusions in this report are those of the authors and do not necessarily represent the official position of the Centers for Disease Control and Prevention. 
Conclusions-Substantially, significant differences in some domains of HRQOL are found between above normal-weight and normal-weight US adolescents. This relationship between BMI and HRQOL is robust and observed among both boys and girls.

\section{Keywords}

Adolescents; Body mass index; Health-related quality of life (HRQOL); National Health and Nutrition Examination Surveys (NHANES); Obesity; Overweight; Underweight

\section{Introduction}

Obesity is a major public health challenge in the United States [1]. The prevalence of obesity among adolescents increased from $5 \%$ in 1976 to $18 \%$ in 2010 [2, 3]. Furthermore, an estimated $15 \%$ of adolescents are overweight [3]. The US Healthy People 2020 process has identified a reduction in the rate of obesity among children and adolescents as an important decennial objective [4]. Obese or overweight adolescents are at a risk of developing psychological problems (e.g., low self-esteem or depression), cardiovascular diseases, and other adverse medical conditions (e.g., metabolic disturbances including type 2 diabetes) [5-11]. However, the association between being obese or overweight and adolescent health-related quality of life (HRQOL) is less clear [12-20]. Additionally, little is known about how being underweight is associated with adolescent HRQOL.

Health-related quality-of-life measures an individual's or group's perceived physical or mental health over time [21, 22]. It assesses the physical, social, and psychological functions of health and well-being. Adolescents with different body weights have been found to have different levels of HRQOL [12-20]. In general, obese or overweight adolescents report worse HRQOL than normal-weight adolescents, but this association with body weight is complex and is not fully examined. Additionally, the magnitude of differences within these groups on reported HRQOL has not been well documented.

Some researchers suggest that obesity or overweight affects all domains of children and adolescents' HRQOL (social, school, psychological, and physical functioning) [12, 14, 15]; others have found that it more profoundly affects physical health $[6,10,11,17,19]$. Some research shows that obesity is associated with impaired social and psychological health [13, 16, 19], whereas others have found no such association [18]. This lack of consensus might result from the use of clinical or small samples with limited generalizability. One exception, however, is that of Swallen et al. [18], who used a nationally representative sample (the US National Longitudinal Study of Adolescent Health), and found that, compared to normalweight adolescents, obese and overweight adolescents reported worse general and physical health but similar mental and social health. Additionally, another study further showed that the association between HRQOL and body weight is sex-specific, but this study used a sample of Australian adolescents [20]. Unfortunately, population-based studies of adolescent obesity and HRQOL are few, and existing studies are often limited to special or non-US. populations [20, 23, 24]. Because of these limitations, the magnitude of differences in the association between HRQOL and body weight for US adolescents has not be determined. To 
better study and track adolescent health in the United States, nationally reliable estimates for this age group are needed.

The Centers for Disease Control and Prevention (CDC) has developed a set of standard HRQOL measures (self-rated health, physically unhealthy days, mentally unhealthy days, and activity limitation days) to monitor population health [21, 22]. Compared to other HRQOL instruments for children and adolescents such as the Pediatric Quality of Life Inventory (PedsQL), the CDC's "Unhealthy Days" measures have unique advantages. For instance, these measures have been included in many population-based datasets for many years and enable the surveillance and comparisons of different health conditions of nationally representative samples of adolescents consistently over time [22]. Although the CDC's measures might have not been widely used on adolescents, they have been found to be valid instruments for this age group [25, 26] and can be used as proxy indicators for adolescent health for generating national baseline estimates. Specifically, since 2001, these core measures have been incorporated into the ongoing National Health and Nutrition Examination Survey (NHANES) [27]. NHANES data are also particularly suitable for examining how adolescent HRQOL is affected by body weight, often represented by body mass index (BMI), nationally over time, because, instead of self-reported heights and weights, these data include more reliable measured heights and weights.

However, to the best of our knowledge, no other studies have examined the associations between adolescent HRQOL based on the CDC's HRQOL measures and BMI from NHANES. No other study has used this dataset to provide prevalence estimates for adolescent HRQOL on a national level in the United States. Therefore, our study aims at measuring the magnitudes of the differences in each domain of the HRQOL measures among adolescents classified by their BMIs. Estimates from our study can be used as national baseline data to compare and evaluate adolescent health status. Because the association between adolescent HRQOL and BMI might vary by sex [3, 18, 20], we stratified by sex to explore the association by BMI category within each sex and also to compare both sexes to each other.

Our study complements previous research by assessing whether HRQOL differed among these four adolescent BMI groups by using a population-based sample. We overcome the limitations of previous research that uses small or unrepresentative samples and are able to determine the magnitude and the direction of associations between HRQOL and BMI among US adolescents. Findings from our study might also be particularly useful for health scientists, professionals, and policy-makers concerned with tracking and improving adolescent health.

\section{Methods}

The 2001-2010 NHANES, a nationally representative multistage cross-sectional survey designed to study the health and nutritional status of the noninstitutionalized US civilian population, provided data for our study [27]. The NHANES program started in the early 1960s and has become an ongoing survey in two-year cycles in the United States since 1991. It collects information on the vital health and nutritional status of the nation and enables 
prevalence estimates of many diseases such as cardiovascular disease or diabetes and risk factors such as smoking and binge drinking. NHANES is funded by the National Center for Health Statistics (NCHS) of the CDC. Its protocol and administration have been approved by the NCHS's Research Ethics Review Board, and all NHANES participants provide informed consent. Different from many other national surveys, NHANES includes a health examination component along with a household interview. The health examination component includes an additional interview, a physical examination, and laboratory tests conducted at a mobile examination center (MEC). During the physical examination, trained health technicians measure participants' height and weight.

NHANES initially screened 7,380 adolescents for interview, $97 \%(=7,087)$ of whom were examined later at the MEC. For this study, we also excluded 56 pregnant girls (see below), leaving 7,031 adolescents 12-17-year old from 2001 through 2010 examined at the MEC. ${ }^{1}$ Among those adolescents, approximately $93 \%$ of them answered questions about their HRQOL. After exclusion of missing values for the covariates included in our study (see Table 1 for the sample sizes in each covariate category), the final analysis sample size varied with the HRQOL measure used-self-rated health $(N=6,017)$, physically unhealthy days ( $N$ $=6,013)$, mentally unhealthy days $(N=6,011)$, and activity limitations days $(N=6,013)$ (Tables 2, 3). We also excluded 56 pregnant girls from our analysis only from 2001 through 2006 since data on adolescent pregnancy status are not publicly available after 2006 . We thus might have inadvertently included some pregnant girls in our analysis since 2007, but pregnancy status did not affect our results because our point estimates did not vary even after including pregnant girls in the analyses (results not shown).

The HRQOL measures in our study include self-rated health, physically unhealthy days, mentally unhealthy days, and activity limitation days [21]. The self-rated health measure is derived from responses to the question "Would you say that in general your health is (1) Excellent, (2) Very Good, (3) Good, (4) Fair, or (5) Poor?" We grouped these responses into fair or poor health, good health, and very good or excellent health. The physically unhealthy days measure is derived from responses to the question, "Now thinking about your physical health, which includes physical illness and injury, for how many days during the past 30 days was your physical health not good?" The mentally unhealthy days measure is derived from responses to the question, "Now thinking about your mental health, which includes stress, depression, and problems with emotions, for about how many days during the past 30 days was your mental health not good?" The activity limitation days measure is derived from responses to the question, "Are you limited in any way in any activities because of physical, mental, or emotional problems?" Because of the skewed distribution of these "unhealthy days" measures and the small sample sizes reporting individual days, we grouped responses for these separate measures into zero days, 1-13, and 14-30 days. ${ }^{2} \mathrm{We}$ recoded responses of "Do not know/Not sure" and "Refused" as missing and excluded them from the analysis. ${ }^{3}$

\footnotetext{
${ }_{1}^{1}$ All of these remaining adolescents had complete records of their measured heights and weights.

2 These cut-off methods have also been used in many previous studies to represent the degree of severity for "Unhealthy Days" measures [34]. For instance, adolescents who reported $\geq 14$ days of mentally unhealthy days would be considered as having frequent mental distress.

${ }^{3}$ Very few adolescents $(<0.1 \%)$ gave "Do not know/Not sure" answers or refused to answer the questions.
} 
We used the BMI, calculated as the weight in kilograms divided by height in meters squared $\left(\mathrm{kg} / \mathrm{m}^{2}\right)$, which correlates with body fatness and classifies adolescents into weight categories that may lead to health problems—obese, overweight, and underweight. BMI has been found to be a valid indicator of body adiposity among obese and overweight adolescents and children [28, 29]. Specifically, we calculated BMI percentiles and z-scores for each adolescent NHANES participant based on the reference population from the CDC's 2000 BMI-for-age growth charts [30]. Based on the recommended cut-off criteria from the CDC, we classified adolescents at or above the 95th percentile of the sex-specific BMI-for-age as obese, between the 85th and 95th percentile as overweight, between the 5th and 85th percentile as normal weight, and under the 5th percentile as underweight [31].

Because some demographic characteristics and risk factors may affect the association between BMI and HRQOL, we adjusted for these variables as potential confounders [1420]. Demographic characteristics controlled for include sex, race/ethnicity (non-Hispanic White, non-Hispanic Black, Mexican American, or Other Race), age (12-14 or 15-17-year old), and the family poverty-income ratio (PIR: low income ( $\leq 30 \%$ ), middle income (>130-350\%), or high income (>350\%)). ${ }^{4}$ Regarding race/ethnicity, we combined all other Hispanics and other races into one category and used Mexican Americans for the Hispanic group based on an analytical guideline from NHANES due to a deficiency in sample sizes for all other Hispanics before 2007 [27]. Risk factors adjusted for include cigarette smoking (Never smoker, Past smoker, or Current smoker) and leisure-time physical inactivity 5 (Physically inactive or Physically active). We also controlled for the interview year based on the calendar years of the five NHANES biennial survey cycles (2001-2002, 2003-2004, 2005-2006, 2007-2008, and 2009-2010). To assess whether sex differences affected the association among BMI categories and reported HRQOL, we used in our models an interaction term ${ }^{6}$ between BMI category and sex, which enabled us to calculate separate estimates for each sex. ${ }^{7}$

We used multinomial logistic regression ${ }^{8}$ to calculate the HRQOL outcomes both as the unadjusted proportions (unadjusted percentages ${ }^{9}$ ) and as predicted marginal percentages ${ }^{10}$ adjusted for potential confounders by BMI categories alone and by these categories within each sex. Because the unadjusted percentages are very similar to the adjusted percentages

\footnotetext{
${ }^{4}$ This variable is an index for the ratio of family income to poverty, based on the Department of Health and Human Services' (HHS) poverty guidelines [27]. In 2008, for a family of four, a PIR of $130 \%$ was equivalent to $\$ 29,000$ and a PIR of $350 \%$ was approximately equivalent to $\$ 77,000[35]$.

5 Adolescents were defined as physically active if they answered yes to either the survey question asking if they ever participated in any vigorous-intensity sports, fitness, or recreational activities or the question asking if they ever participated in any moderateintensity sports, fitness, or recreational activities. Adolescents were classified physically inactive if they answered no to both of these questions.

${ }^{6}$ The software we used, SAS-callable SUDAAN 10, requires creating interaction terms to obtain predicted marginal proportions for each sex.

${ }^{7} \mathrm{We}$ also examined the interactions between BMI and income as well as between BMI and race/ethnicity, and found that these interactions were not statistically significant after controlling for all other covariates in the model and thus were not reported. ${ }^{8}$ Originally, we considered other statistical models such as proportional-odds ordinal logistic regression, but the proportional-odds assumption was not met. Because we are more interested in estimating the magnitude of differences such as percentages for our outcome variables, the nominal multinomial logistic regression model fits our data adequately with fewer assumptions.

${ }^{9}$ We chose to report percentages because, based on our experience, they are more easily understood than other statistics such as odds ratios and regression coefficients.

${ }^{10}$ These adjusted percentages are based on the predicted marginal proportions estimated from the multinomial logistic regression as the average of the predicted responses in each category if all the respondents had been in that category after adjustment for the covariates.
} 
(the differences between them range from 0.7 to $5.1 \%$ ), we report only adjusted percentages and their $95 \%$ confidence intervals (CI) (Tables 2, 3). We also estimated the adjusted odds ratios ("Adjusted OR") for different BMI categories relative to normal-weight adolescents to assess the associations between BMI and HRQOL. We presented these Adjusted OR in Table 4 of the Appendix, but did not include them in Tables 2 and 3 because odds ratios can be calculated from the percentages in these tables, but the percentages cannot be calculated from the odds ratios. Moreover, the tabulated percentages enable comparisons among all the BMI groups, but the odds ratios require specifying an arbitrary reference group. In crosssectional studies like this one, finally, odds ratios may also exaggerate relative risks between group percentages when the percentage in the reference group is large [32]. Because nonoverlapping $95 \% \mathrm{CI}$ imply statistically significant differences (below the significance level of 0.05) between percentages in Table 2 and 3, we did not report $P$ values associated with $t$ tests or Wald chi-square tests for the comparisons between BMI categories on HRQOL outcomes to avoid redundancy. Additionally, we also presented results from multinomial logistic regression such as odds ratios and their $95 \%$ confidence intervals for all other confounders/covariates in Table 4 of the Appendix for reference purpose, but did not discuss them in the Results section. ${ }^{11}$ We performed all analyses in SAS-callable SUDAAN 10.0 to account for respondent sample MEC weights and the strata and the primary sampling units in NHANES' complex sample survey design [33].

\section{Results}

\section{Descriptive statistics}

Overall, $18 \%$ of adolescents aged 12-17-year old were classified as obese, $16 \%$ as overweight, $62 \%$ as normal weight, and $5 \%$ as underweight (Table 1). Sixty-two percent of our sample was non-Hispanic White, and $50 \%$ from 15-to-17-year old. Approximately, 81 $\%$ reported never-smoking cigarettes, but $11 \%$ reported currently smoking. Finally, $88 \%$ reported being physically active.

\section{Self-rated health}

Obese and overweight adolescents reported significantly worse self-rated health than normal-weight adolescents. Only $37 \%$ of obese adolescents and $54 \%$ of overweight adolescents reported excellent or very good health, significantly less than normal-weight adolescents (65\%) after adjusting for demographic characteristics, cigarette smoking, physical activity, and interview year (Table 2). Compared to normal-weight adolescents, obese adolescents reported excellent or very good health relative to good health $60 \%$ less often (Adjusted OR 0.4, $95 \%$ CI OR 0.3-0.4) and overweight adolescents, $40 \%$ less often (Adjusted OR 0.6, $95 \%$ CI 0.5-0.8). Nineteen percent of obese adolescents reported fair or poor health compared to $5 \%$ of normal-weight adolescents (Adjusted OR 2.6, $95 \%$ CI 2.03.5). Underweight adolescents reported excellent or very good health about as often as normal-weight adolescents.

\footnotetext{
${ }^{11}$ Although the effects of these covariates (e.g., race/ethnicity and PIR) on adolescent HRQOL are of interest to many researchers, we did not discuss them in the Results section because the main focus of our paper was to examine the relationship between BMI and HRQOL after controlling/adjusting for these confounders/covariates.
} 
Generally, the direction of the association between BMI categories and self-rated health did not vary by sex (Table 3). Obese and overweight boys and girls both reported significantly worse self-rated health than normal-weight boys and girls. Specifically, $19 \%$ of obese boys and $20 \%$ of obese girls reported fair or poor health, significantly higher than that in normalweight boys (5\%) and girls (6\%). Sixty-nine percent of normal-weight boys reported excellent or very good health, significantly more than that in any other BMI category (obese boys: $40 \%$; overweight boys: $59 \%$; underweight boys: $53 \%$ ). Similarly, $62 \%$ of normalweight girls reported excellent or very good health, significantly greater than that in overweight girls (49\%) and obese girls (34\%) but not that in underweight girls (62\%).

Boys also generally reported better self-rated health than girls. The percentage of normalweight boys reporting excellent or very good health significantly exceeded that for all girl BMI categories except that for underweight girls (Table 3).

\section{Physically unhealthy days}

The percentages in different categories of reported physically unhealthy days did not differ statistically significantly across the BMI categories overall (Table 2) or for either boys or girls (Table 3).

\section{Mentally unhealthy days}

Overall, mentally unhealthy days did not statistically significantly differ across the BMI categories (Table 2). This lack of association between mentally unhealthy days and BMI categories occurred among both boys and girls (Table 3). However, boys generally reported better mental health than girls. Specifically, $65 \%$ of normal-weight boys reported zero mentally unhealthy days, significantly higher than comparable percentages among any girl BMI categories. Significantly, more overweight boys (62\%) and obese boys (62\%) reported zero mentally unhealthy days than not only obese girls (48\%) but also normalweight girls $(51 \%)$.

\section{Activity limitation days}

All BMI categories reported similar percentages of activity limitation days. This lack of differences did not change within each sex. However, $82 \%$ of normal-weight boys and $83 \%$ of obese boys reported zero activity limitation days, both significantly more than the $70 \%$ of obese girls who reported zero activity limitation days (Table 3).

\section{Discussion}

Previous studies have shown inconsistent or contradictory conclusions regarding the relationships between adolescent BMI categories and HRQOL. However, many of these studies were based on small and unrepresentative clinical or school samples. These studies often used standardized measures such as Pediatric Quality of Life Inventory (PedsQL) to assess adolescent HRQOL [12, 15, 18, 20], but these measures are often not included in national ongoing surveillance data in the United States because of their length. Because of this limitation in sampling, comparisons of different health outcomes and diseases for adolescents across years might be problematic. In contrast, the CDC's HRQOL measures are 
comparable with other measures and may be particularly useful for tracking adolescent health on a national level over time. Our study thus extended previous studies by using a large population-based sample over several years and the CDC's HRQOL measures. Our study also fills in a gap in previous research by assessing the magnitude of differences between HRQOL outcomes within each BMI category. To the best of our knowledge, our study is the first that provides national prevalence estimates for adolescent HRQOL by BMI in the United States. Findings from our study can be used as baseline estimates for future research.

Consistent with previous research, obese and overweight adolescents reported worse selfrated health than normal-weight adolescents. Substantial gaps are found between normalweight and obese and overweight adolescents. Because obese and overweight adolescents might generally experience more psychological problems such as depression and are at a higher risk of developing adverse medical conditions such as cardiovascular disease and diabetes, it is not surprising that they are more likely to report worse general health [5-8]. Although previous studies have consistently found obesity to have a significant impact on physical health, this consistency is less obvious regarding its impact on mental health [1219]. Our study did not find any other significant differences between BMI categories in terms of reported physical or mental health or in reported activity limitation days. The discrepancies between our and others' studies might be due to the different physical and mental health measures used. Importantly, we also did not find significant differences in reported HRQOL between underweight and normal-weight adolescents. Although the small sample of underweight adolescents may have reduced the statistical power to detect differences, this finding is still noteworthy since no other study has documented underweight adolescents' HRQOL in a nationally representative sample.

Different from one recent study on Australian adolescents [20], after stratifying on sex, we found no sex-specific patterns between BMI and HRQOL among US adolescents. As with the overall sample, normal-weight boys and girls generally reported better HRQOL than overweight and obese boys and girls with respect to self-rated health but not to physical health, mental health, or activity limitation.

Furthermore, our findings support those in previous studies that have shown boys generally report better health than girls [3, 18]. In our study, compared to most BMI categories in girls, normal-weight boys reported better self-rated health and mental health but not better physical health and activity limitation. We also found that obese boys reported better selfrated health, mental health, and fewer activity limitation days than obese girls.

Our study is subject to several limitations. First, although the four CDC HRQOL measures have face validity, the "Healthy Days" measures (physically, mentally, and activity limitation days) might not be sensitive enough to detect differences among adolescents. One report on the cognitive testing of the CDC's HRQOL measures suggests that adolescents may rate their health accurately but are less likely to take into account the 30-day time frame when reporting the "Healthy Days" measures [25]. Another study of adolescents has also shown that self-rated health correlates only weakly with the "Healthy Days" measures [26]. Therefore, the insensitivity of our measures might have reduced our ability to detect 
differences in this study. Compared to multiple item, standardized adolescent HRQOL scales, the four-item CDC HRQOL measures are broader and may also not be sensitive enough to distinguish differences among specific HRQOL domains. Additionally, the distributions for the "Unhealthy Days" measures were skewed because a large proportion of adolescents reported zero physically and mentally unhealthy days as well as zero activity limitation days. Consequently, these measures might not discriminate well among those who reported better health (for instance, zero unhealthy days). Second, NHANES HRQOL data are self-reported and not corroborated by others (for example, parents, teachers), making them subject to misclassification. Thus, adolescents' ability to correctly understand and interpret the questions might have affected our findings. Third, because the NHANES is cross-sectional, the associations we observed may not be causal and may result from potential confounders. Although we adjusted for several confounders in our study, and although these adjustments did not change our findings, we still may have omitted other important confounders. For example, we did not adjust for more specific health outcomes or comorbidities, such as diabetes mellitus and cardiovascular disease, which are associated with BMI and affect HRQOL [8-11], because the prevalence of such comorbidities among adolescents in this population-based study was too small to affect this study's findings. Moreover, we also did not adjust for other more common chronic diseases among adolescents such as asthma in our final report because we found it did not significantly change the association between BMI and HRQOL. However, future, larger, populationbased studies should consider adjusting for these comorbidities if their prevalence is high enough among adolescents or if they significantly affect adolescent HRQOL. Finally, NHANES does not have information on variables such as parental education or body image, so that we could not examine their effects on the association between BMI and HRQOL.

In conclusion, despite certain limitations, our study expanded on previous research and demonstrated a robust association between poor self-rated health and being obese and overweight among a population-based sample of adolescents in the United States. Results from our study show that statistically significant gaps exist between adolescents who are above normal weight and normal weight. Findings from our study might be particularly useful for policy-makers and health professionals who utilize national estimates and want to monitor adolescent health and to develop interventions for addressing obesity and quality of life among adolescents.

\section{Acknowledgments}

The project was undertaken while Dr. Cui was under contract with CDC through the Oak Ridge Institute for Science and Education (ORISE) fellowship program.

\section{Abbreviations}

$\begin{array}{ll}\text { HRQOL } & \text { Health-related quality of life } \\ \text { BMI } & \text { Body mass index } \\ \text { NHANES } & \text { National Health and Nutrition Examination Surveys } \\ \text { MEC } & \text { Mobile examination center }\end{array}$




\section{References}

1. U.S. Department of Health and Human Services. The Surgeon General's vision for a healthy and fit nation. Rockville, MD: U.S. Department of Health and Human Services, Office of the Surgeon General; 2010.

2. Ogden, C.; Carroll, M. Prevalence of obesity among children and adolescents: United States, trends 1963-1965 through 2007-2008. Atlanta: Centers for Disease Control and Prevention National Center for Health Statistics; 2012. http://www.cdc.gov/nchs/data/hestat/obesity_child_07_08/ obesity_child_07_08.pdf [Accessed November 2, 2012]

3. Ogden CL, Carroll MD, Kit BK, et al. Prevalence of obesity and trends in body mass index among US children and adolescents, 1999-2010. JAMA. 2012; 307:483-490. [PubMed: 22253364]

4. U.S. Department of Health and Human Services. Healthy People 2020. Washington, DC: 2012. Office of disease prevention and health promotion. http://www.healthypeople.gov/2020/ topicsobjectives2020/objectiveslist.aspx?topicId=29 [Accessed November 10, 2012]

5. Must A. Morbidity and mortality associated with elevated body weight in children and adolescents. The American Journal of Clinical Nutrition. 1996; 63(3):445S-447S. [PubMed: 8615339]

6. Dietz WH. Health consequences of obesity in youth: childhood predictors of adult disease. Pediatrics. 1998; 101(3):518-525. [PubMed: 12224658]

7. Kolotkin RL, Zeller M, Modi AC, Samsa GP, Quinlan NP, Yanovski JA, et al. Assessing weightrelated quality of life in adolescents. Obesity. 2012; 14(3):448-457. [PubMed: 16648616]

8. Varni JW, Burwinkle TM, Jacobs JR, Gottschalk M, Kaufman F, Jones KL. The PedsQL in type 1 and type 2 diabetes reliability and validity of the pediatric quality of life inventory generic core scales and type 1 diabetes module. Diabetes Care. 2003; 26(3):631-637. [PubMed: 12610013]

9. Sinha R, Fisch G, Teague B, et al. Prevalence of impaired glucose tolerance among children and adolescents with marked obesity. New England Journal Medicine. 2002; 346(11):802-810.

10. Varni JW, Limbers CA, Burwinkle TM. Impaired health-related quality of life in children and adolescents with chronic conditions: A comparative analysis of 10 disease clusters and 33 disease categories/severities utilizing the PedsQL ${ }^{\mathrm{TM}} 4.0$ Generic Core Scales. Health and Quality of Life Outcomes. 2007; 5:43. http://www.ncbi.nlm.nih.gov/pmc/articles/PMC1964786/pdf/ 1477-7525-5-43.pdf. [PubMed: 17634123]

11. Freedman DS, Dietz WH, Srinivasan SR, Berenson GS. The relation of overweight to cardiovascular risk factors among children and adolescents: The Bogalusa Heart Study. Pediatrics. 1999; 103(6 pt 1):1175-1182. [PubMed: 10353925]

12. Ul-Haq, Z.; Mackay, DF.; Fenwick, E., et al. [Accessed November 9, 2012] Meta-analysis of the association between body mass index and health-related quality of life among children and adolescents, assessed using the Pediatric Quality of Life Inventory Index. The Journal of Pediatrics. 2012. http://www.ncbi.nlm.nih.gov/pubmed/22959137

13. Pinhas-Hamiel O, Singer S, Pilpel N, Fradkin A, Modan D, Reichman B. Health-related quality of life among children and adolescents: associations with obesity. International Journal of Obesity. 2005; 30(2):267-272. [PubMed: 16231035]

14. Tsiros MD, Olds T, Buckley JD, Grimshaw P, Brennan L, Walkley J, et al. Health-related quality of life in obese children and adolescents. International Journal of Obesity. 2009; 33(4):387-400. [PubMed: 19255583]

15. Schwimmer JB, Burwinkle TM, Varni JW. Health-related quality of life of severely obese children and adolescents. JAMA. 2003; 289(14):1813-1819. [PubMed: 12684360]

16. Zeller MH, Modi AC. Predictors of health-related quality of life in obese youth. Obesity. 2012; 14(1):122-130. [PubMed: 16493130] 
17. Doll HA, Petersen SE, Stewart-Brown SL. Obesity and physical and emotional well-being: associations between body mass index, chronic illness, and the physical and mental components of the SF-36 questionnaire. Obesity Research. 2000; 8(2):160-170. [PubMed: 10757202]

18. Swallen KC, Reither EN, Haas SA, Meier AM. Overweight, obesity, and health-related quality of life among adolescents: the National Longitudinal Study of Adolescent Health. Pediatrics. 2005; 115(2):340-347. [PubMed: 15687442]

19. Williams J, Wake M, Hesketh K, Maher E, Waters E. Health-related quality of life of overweight and obese children. JAMA. 2005; 293:70-76. [PubMed: 15632338]

20. Gopinath, B.; Baur, LA.; Burlutsky, G.; Mitchell, P. [Accessed February 4, 2013] Adiposity adversely influences quality of life among adolescents. Journal of Adolescent Health. 2013. http:// www.sciencedirect.com/science/article/pii/S1054139X12007884

21. Centers for Disease Control and Prevention (CDC). Measuring health days: Population assessment of health-related quality of life. Atlanta, GA: US Department of Health and Human Services, CDC; 2000. http://www.cdc.gov/hrqol/pdfs/mhd.pdf [Accessed September 20, 2012]

22. Moriarty DG, Zack MM, Kobau R. The centers for disease control and prevention's healthy days measures-Population tracking of perceived physical and mental health over time. Health and Quality of Life Outcomes. 2003; 1:37. http://www.ncbi.nlm.nih.gov/pmc/articles/PMC201011/. [PubMed: 14498988]

23. Keating CL, Moodie ML, Swinburn BA. The health-related quality of life of overweight and obese adolescents-A study measuring body mass index and adolescent-reported perceptions. International Journal of Pediatric Obesity. 2001; 6(5-6):434-441. [PubMed: 21774577]

24. Williams JW, Canterford L, Hesketh KD, et al. Changes in body mass index and health related quality of life from childhood to adolescence. International Journal of Pediatric Obesity. 2011; 6:e442-e448. [PubMed: 21198354]

25. Research Support Services, Inc. Cognitive testing of HRQOL interview guide for adolescents. Findings. 2011

26. Zullig KJ, Valois RF, Huebner ES, et al. Evaluating the performance of the Centers for Disease Control and Prevention core Health-Related Quality of Life scale with adolescents. Public Health Reports. 2004; 119(6):577-584. [PubMed: 15504449]

27. Centers for Disease Control and Prevention (CDC). National Center for Health Statistics (NCHS), National Health and Nutrition Examination Survey Data. Hyattsville, MD: U.S. Department of Health and Human Services, Centers for Disease Control and Prevention (CDC); 2012. 20012010. http://www.cdc.gov/nchs/nhanes/nhanes_questionnaires.htm [Accessed September 20, 2012]

28. Freedman DS, Wang J, Thornton JC, et al. Classification of body fatness by body mass index-orage categories among children. Archives of Pediatrics and Adolescent Medicine. 2009; 163(9): 805-811. [PubMed: 19736333]

29. Freedman DS, Sherry B. The validity of BMI as an indicator of body fatness and risk among children. Pediatrics. 2009; 124(Supplement 1):S23-S34. [PubMed: 19720664]

30. Centers for Disease Control and Prevention, National Center for Health Statistics. [Accessed October 10, 2012] CDC growth charts: United States. 2012. http://www.cdc.gov/growthcharts/

31. Ogden, CL.; Flegal, KM. National health statistics reports. Hyattsville, MD: National Center for Health Statistics; 2010. Changes in terminology for childhood overweight and obesity. http:// www.cdc.gov/nchs/data/nhsr/nhsr025.pdf [Accessed October 10, 2012]

32. Thompson ML, Myers JE, Kriebel D. Prevalence odds ratio or prevalence ratio in the analysis of cross sectional data: what is to be done? Occupational and Environmental Medicine. 1998; 55(4): 272-277. [PubMed: 9624282]

33. Research Triangle Institute. SUDAAN language manual, release 10.0. Research Triangle Park (NC): Research Triangle Institute; 2010.

34. Brown DW, Balluz LS, Heath GW, Moriarty DG, Ford ES, Giles WH, et al. Associations between recommended levels of physical activity and health-related quality of life findings from the 2001 behavioral risk factor surveillance system (BRFSS) survey. Preventive Medicine. 2003; 37(5): 520-528.10.1016/S0091-7435(03)00179-8 [PubMed: 14572437] 
35. Ogden, CL.; Lamb, MM.; Carroll, MD.; Flegal, KM. Obesity and socioeconomic status in children: United Sates 198801994 and 2005-2008. NCHS data brief no 51. Hyattsville, MD: National Center for Health Statistics; 2010.

\section{Appendix}

See Tables $1-4$.

\section{Table 1}

Body mass index categories, sociodemographic characteristics, risky behaviors, and interview years among adolescents, 12-17-year old-National Health and Nutrition Examination Survey, 2001-2010 $(N=7,031)$

\begin{tabular}{|c|c|c|}
\hline Characteristics & Sample size & Weighted percentage ${ }^{a}$ \\
\hline \multicolumn{3}{|l|}{ Body mass index categories } \\
\hline Underweight & 292 & 4.5 \\
\hline Normal weight & 4,175 & 61.9 \\
\hline Overweight & 1,150 & 15.9 \\
\hline Obese & 1,414 & 17.7 \\
\hline \multicolumn{3}{|l|}{ Sex } \\
\hline Boys & 3,585 & 50.5 \\
\hline Girls & 3,446 & 49.5 \\
\hline \multicolumn{3}{|l|}{ Race/ethnicity } \\
\hline Non-Hispanic White & 2,020 & 61.5 \\
\hline Non-Hispanic Black & 2,175 & 14.5 \\
\hline Mexican American & 2,090 & 11.8 \\
\hline All other race & 746 & 12.2 \\
\hline \multicolumn{3}{|l|}{ Age } \\
\hline 12-14-year old & 3,522 & 50.0 \\
\hline 15-17-year old & 3,509 & 50.0 \\
\hline \multicolumn{3}{|c|}{ Family poverty-income ratio $b$} \\
\hline Low-income family & 2,594 & 27.8 \\
\hline Middle-income family & 2,512 & 37.2 \\
\hline High-income family & 1,497 & 35.0 \\
\hline \multicolumn{3}{|l|}{ Cigarette smoking $c$} \\
\hline Never smoker & 5,208 & 80.8 \\
\hline Past smoker & 569 & 8.3 \\
\hline Current smoker & 602 & 10.9 \\
\hline \multicolumn{3}{|l|}{ Physical inactivity $d$} \\
\hline Physically active & 5,794 & 88.3 \\
\hline Physically inactive & 853 & 11.7 \\
\hline \multicolumn{3}{|l|}{ Interview year } \\
\hline $2001-2002$ & 1,827 & 19.9 \\
\hline 2003-2004 & 1,654 & 19.5 \\
\hline $2005-2006$ & 1,613 & 20.0 \\
\hline
\end{tabular}




\begin{tabular}{crr}
\hline Characteristics & Sample size & Weighted percentage $^{\boldsymbol{a}}$ \\
\hline $2007-2008$ & 933 & 20.2 \\
$2009-2010$ & 1,004 & 20.4 \\
\hline
\end{tabular}

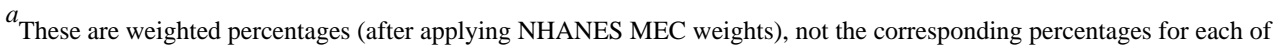
the variable based on their sample sizes in the preceding column

$b_{\text {Sample size }}=6,603$ (excluding missing values)

${ }^{c}$ Sample size $=6,379$ (excluding missing values)

$d_{\text {Sample size }}=6,647$ (excluding missing values)

Table 2

Adjusted percentages of the CDC'S health-related quality-of-life measures among adolescents, 12-17-year old, by body mass index category-National Health and Nutrition Examination Survey, 2001-2010

\begin{tabular}{|c|c|c|c|c|}
\hline $\begin{array}{l}\text { Body mass index } \\
\text { category }\end{array}$ & $N$ & $\begin{array}{c}\text { Excellent/very good } \\
\text { Percentages (95 \% CI) }\end{array}$ & $\begin{array}{c}\text { Good Percentages (95 } \\
\% \text { CI) }\end{array}$ & $\begin{array}{c}\text { Fair/poor Percentages } \\
(95 \% \text { CI })\end{array}$ \\
\hline \multicolumn{5}{|l|}{ Self-rated health } \\
\hline Underweight & 199 & $56.3(46.9-65.3)$ & $34.1(25.9-43.3)$ & $9.7(5.6-16.2)$ \\
\hline Normal weight & 3,633 & $65.2(63.1-67.2)$ & $29.7(27.6-31.8)$ & $5.2(4.2-6.2)$ \\
\hline Overweight & 972 & $53.8(50.1-57.5)$ & $37.5(33.8-41.3)$ & $8.7(6.8-11.1)$ \\
\hline \multirow[t]{2}{*}{ Obese } & 1,213 & $37.1(33.2-41.2)$ & $43.9(40.0-47.7)$ & $19.1(15.9-22.7)$ \\
\hline & & 0 days & $1-13$ days & 14-30 days \\
\hline \multicolumn{5}{|c|}{ Physically unhealthy days } \\
\hline Underweight & 199 & $53.9(44.2-63.3)$ & $42.6(34.2-51.5)$ & $3.5(1.2-9.6)$ \\
\hline Normal weight & 3,630 & $59.6(57.2-61.9)$ & $36.1(33.8-38.5)$ & $4.3(3.4-5.4)$ \\
\hline Overweight & 971 & $65.6(60.9-70.0)$ & $31.9(27.9-36.2)$ & $2.5(1.5-4.3)$ \\
\hline Obese & 1,213 & $60.7(57.1-64.1)$ & $34.1(30.5-37.9)$ & $5.2(3.7-7.4)$ \\
\hline \multicolumn{5}{|c|}{ Mentally unhealthy days } \\
\hline Underweight & 199 & $48.7(39.4-58.2)$ & $40.2(30.8-50.4)$ & $11.0(5.2-21.8)$ \\
\hline Normal weight & 3,628 & $58.0(55.8-60.1)$ & $35.8(33.8-37.8)$ & $6.2(5.3-7.4)$ \\
\hline Overweight & 971 & $57.2(52.6-61.7)$ & $34.5(30.7-38.6)$ & $8.2(6.0-11.2)$ \\
\hline Obese & 1,213 & $55.4(52.0-58.8)$ & $37.5(34.2-41.0)$ & $7.0(5.2-9.5)$ \\
\hline \multicolumn{5}{|c|}{ Activity limitation days } \\
\hline Underweight & 198 & $76.7(67.4-84.0)$ & $19.7(13.6-27.8)$ & $3.6(1.1-10.8)$ \\
\hline Normal weight & 3,630 & $79.2(76.9-81.3)$ & $18.8(16.9-20.8)$ & $2.0(1.4-2.9)$ \\
\hline Overweight & 972 & $78.9(74.8-82.5)$ & $19.3(15.9-23.2)$ & $1.8(1.0-3.2)$ \\
\hline Obese & 1,213 & $77.2(73.6-80.4)$ & $19.8(16.7-23.3)$ & $3.0(1.9-4.8)$ \\
\hline
\end{tabular}

Model adjusted for demographic characteristics (sex, race/ethnicity, age, and family poverty-income ratio), risky behaviors (smoking status and physical inactivity), and interview years (NHANES survey cycles)

$N$ sample sizes (excluding missing values), $95 \%$ CI $95 \%$ Confidence intervals for adjusted percentages 


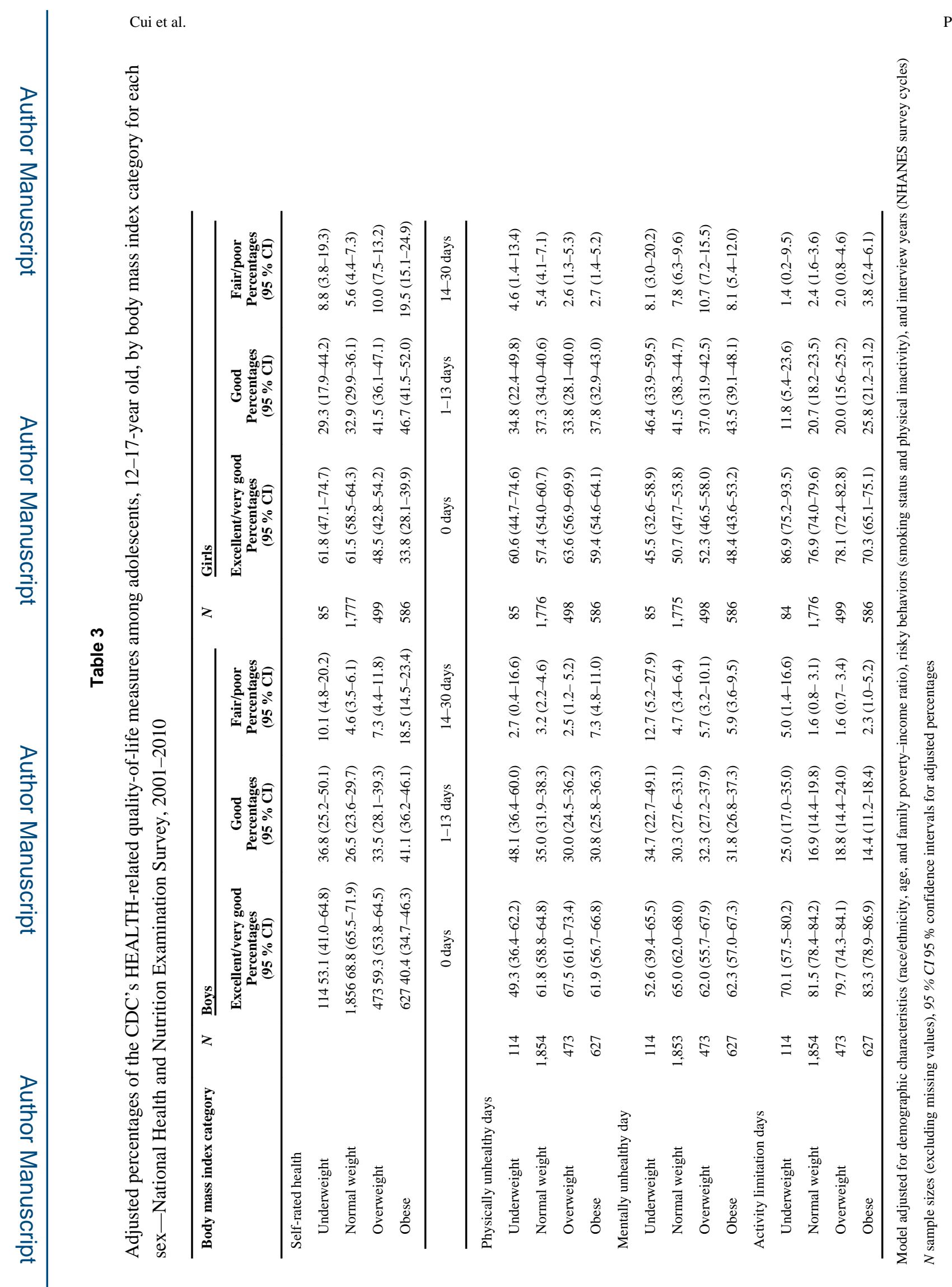

Qual Life Res. Author manuscript; available in PMC 2015 October 11. 


\section{Table 4}

Results of multinomial logistic regression: odds ratios for the body mass index categories and all covariates among adolescents, 12-17 years old-National Health and Nutrition Examination Survey, 2001-2010

\begin{tabular}{|c|c|c|c|c|}
\hline & \multicolumn{2}{|c|}{ Excellent/very good versus good } & \multicolumn{2}{|l|}{$\underline{\text { Fair/poor versus good }}$} \\
\hline & Odds ratio $(95 \% \mathrm{CI})$ & $P$ values & Odds ratio $(95 \% \mathrm{CI})$ & $P$ values \\
\hline \multicolumn{5}{|l|}{ Self-rated health } \\
\hline \multicolumn{5}{|c|}{ Body mass index (ref: normal weight) } \\
\hline Underweight & $0.7(0.5-1.1)$ & & $1.6(0.8-3.3)$ & \\
\hline Overweight & $0.6(0.5-0.8)$ & $<.0001$ & $1.4(0.9-2.0)$ & \\
\hline Obese & $0.4(0.3-0.4)$ & $<.0001$ & $2.6(2.0-3.5)$ & $<.0001$ \\
\hline \multicolumn{5}{|l|}{ Sex (ref: girls) } \\
\hline Boys & $1.4(1.2-1.6)$ & $<.0001$ & $1.0(0.8-1.3)$ & \\
\hline \multicolumn{5}{|l|}{ Race (ref: all other race) } \\
\hline Non-Hispanic White & $1.1(0.8-1.5)$ & & $1.1(0.6-1.8)$ & \\
\hline Non-Hispanic Black & $0.8(0.5-1.1)$ & & $1.4(0.8-2.5)$ & \\
\hline Mexican American & $0.6(0.4-0.8)$ & .0016 & $1.2(0.7-2.1)$ & \\
\hline \multicolumn{5}{|l|}{ Age (ref: 15-17 years old) } \\
\hline $12-14$ years old & $0.9(0.8-1.1)$ & & $1.1(0.8-1.4)$ & \\
\hline \multicolumn{5}{|c|}{ Family poverty-income ratio (ref: high-income families) } \\
\hline Low-income families & $0.7(0.6-0.8)$ & .0004 & $1.4(1.0-2.0)$ & \\
\hline Middle-income families & $0.8(0.7-10)$ & .0394 & $1.7(1.2-2.4)$ & .003 \\
\hline \multicolumn{5}{|c|}{ Cigarette smoking (ref: current smokers) } \\
\hline Never smokers & $2.3(1.8-3.0)$ & $<.0001$ & $0.8(0.6-1.2)$ & \\
\hline Past smokers & $1.5(1.1-2.1)$ & $<.0168$ & $1.0(0.6-1.6)$ & \\
\hline \multicolumn{5}{|c|}{ Physical inactivity (ref: physically inactive) } \\
\hline Physically active & $1.3(1.0-1.6)$ & & $0.8(0.5-1.1)$ & \\
\hline \multicolumn{5}{|c|}{ Interview year (ref: 2009-2010) } \\
\hline $2001-2002$ & $1.5(1.1-2.0)$ & .0063 & $0.7(0.4-1.1)$ & \\
\hline 2003-2004 & $1.5(1.1-2.0)$ & .0037 & $0.6(0.4-1.1)$ & \\
\hline 2005-2006 & $1.2(0.9-1.5)$ & & $0.8(0.5-1.3)$ & \\
\hline \multirow[t]{2}{*}{$2007-2008$} & $1.1(0.8-1.5)$ & & $0.9(0.5-1.5)$ & \\
\hline & $1-13$ versus 0 days & & $14-30$ versus 0 days & \\
\hline \multicolumn{5}{|l|}{ Physically unhealthy days } \\
\hline \multicolumn{5}{|c|}{ Body mass index (ref: normal weight) } \\
\hline Underweight & $1.3(0.9-1.9)$ & & $0.9(0.3-2.9)$ & \\
\hline Overweight & $0.8(0.6-1.0)$ & 0.0381 & $0.5(0.3-1.0)$ & .0459 \\
\hline Obese & $0.9(0.8-1.1)$ & & $1.2(0.8-1.8)$ & \\
\hline \multicolumn{5}{|l|}{ Sex (ref: girls) } \\
\hline Boys & $0.9(0.8-1.0)$ & & $0.8(0.5-1.2)$ & \\
\hline
\end{tabular}

Qual Life Res. Author manuscript; available in PMC 2015 October 11. 


\begin{tabular}{|c|c|c|c|c|}
\hline & \multicolumn{2}{|c|}{$\underline{\text { Excellent/very good versus good }}$} & \multicolumn{2}{|l|}{$\underline{\text { Fair/poor versus good }}$} \\
\hline & Odds ratio $(95 \% \mathrm{CI})$ & $P$ values & Odds ratio $(95 \% \mathrm{CI})$ & $P$ values \\
\hline Non-Hispanic White & $0.7(0.5-1.0)$ & & $1.4(0.6-3.1)$ & \\
\hline Non-Hispanic Black & $0.6(0.4-0.8)$ & .0017 & $0.8(0.4-1.8)$ & \\
\hline Mexican American & $0.6(0.4-0.8)$ & .0004 & $0.6(0.3-1.4)$ & \\
\hline \multicolumn{5}{|l|}{ Age (ref: $15-17$ years old) } \\
\hline $12-14$ years old & $1.0(0.9-1.2)$ & & $1.0(0.6-1.6)$ & \\
\hline \multicolumn{5}{|c|}{ Family poverty-income ratio (ref: high-income families) } \\
\hline Low-income families & $0.9(0.7-1.1)$ & & $1.1(0.7-1.8)$ & \\
\hline Middle-income families & $0.9(0.7-1.1)$ & & $1.0(0.7-1.6)$ & \\
\hline \multicolumn{5}{|c|}{ Cigarette smoking (ref: current smokers) } \\
\hline Never smokers & $0.7(0.6-1.0)$ & .0418 & $0.5(0.3-0.8)$ & .0024 \\
\hline Past smokers & $0.7(0.5-1.0)$ & .0473 & $0.7(0.4-1.4)$ & \\
\hline \multicolumn{5}{|c|}{ Physical inactivity (ref: physically inactive) } \\
\hline Physically active & $1.4(1.1-1.8)$ & .0029 & $1.0(0.5-1.9)$ & \\
\hline \multicolumn{5}{|c|}{ Interview year (ref: 2009-2010) } \\
\hline $2001-2002$ & $0.9(0.7-1.2)$ & & $1.2(0.6-2.3)$ & \\
\hline 2003-2004 & $0.7(0.5-0.9)$ & .0115 & $1.1(0.5-2.4)$ & \\
\hline $2005-2006$ & $0.7(0.6-1.0)$ & .0289 & $0.9(0.4-1.9)$ & \\
\hline $2007-2008$ & $1.0(0.7-1.3)$ & & $1.3(0.6-2.7)$ & \\
\hline \multicolumn{5}{|l|}{ Mentally unhealthy days } \\
\hline \multicolumn{5}{|c|}{ Body mass index (ref: normal weight) } \\
\hline Underweight & $1.4(0.9-2.1)$ & & $2.2(0.9-5.4)$ & \\
\hline Overweight & $1.0(0.8-1.2)$ & & $1.3(0.9-2.1)$ & \\
\hline Obese & $1.1(1.0-1.3)$ & & $1.2(0.8-1.7)$ & \\
\hline \multicolumn{5}{|l|}{ Sex (ref: girls) } \\
\hline Boys & $0.6(0.5-0.7)$ & $<.0001$ & $0.5(0.3-0.7)$ & $<.0001$ \\
\hline \multicolumn{5}{|l|}{ Race (ref: all other race) } \\
\hline Non-Hispanic White & $0.8(0.5-1.1)$ & & $1.0(0.5-1.8)$ & \\
\hline Non-Hispanic Black & $0.6(0.4-0.9)$ & .0100 & $0.6(0.3-1.1)$ & \\
\hline Mexican American & $0.6(0.4-0.9)$ & .0041 & $0.5(0.3-0.9)$ & .0168 \\
\hline \multicolumn{5}{|l|}{ Age (ref: 15-17 years old) } \\
\hline $12-14$ years old & $0.9(0.7-1.0)$ & & $0.7(0.5-1.0)$ & \\
\hline \multicolumn{5}{|c|}{ Family poverty-income ratio (ref: high-income families) } \\
\hline Low-income families & $1.1(0.9-1.4)$ & & $1.3(0.9-1.9)$ & \\
\hline Middle-income families & $1.0(0.9-1.2)$ & & $1.4(0.9-2.1)$ & \\
\hline \multicolumn{5}{|c|}{ Cigarette smoking (ref: current smokers) } \\
\hline Never smokers & $0.5(0.4-0.6)$ & $<.0001$ & $0.3(0.2-0.5)$ & $<.0001$ \\
\hline Past smokers & $0.7(0.5-1.0)$ & .0279 & $0.7(0.4-1.2)$ & \\
\hline \multicolumn{5}{|c|}{ Physical Inactivity (ref: physically inactive) } \\
\hline Physically active & $1.5(1.1-1.9)$ & .0019 & $1.0(0.7-1.5)$ & \\
\hline \multicolumn{5}{|c|}{ Interview year (ref: 2009-2010) } \\
\hline $2001-2002$ & $0.7(0.5-0.9)$ & .0017 & $0.4(0.3-0.6)$ & $<.0001$ \\
\hline
\end{tabular}

Qual Life Res. Author manuscript; available in PMC 2015 October 11. 


\begin{tabular}{|c|c|c|c|c|}
\hline & \multicolumn{2}{|c|}{$\underline{\text { Excellent/very good versus good }}$} & \multicolumn{2}{|l|}{ Fair/poor versus good } \\
\hline & Odds ratio (95\% CI) & $P$ values & Odds ratio (95 \% CI) & $P$ values \\
\hline 2003-2004 & $0.6(0.5-0.7)$ & $<.0001$ & $0.4(0.2-0.7)$ & .0008 \\
\hline 2005-2006 & $0.6(0.5-0.8)$ & $<.0001$ & $0.4(0.2-0.6)$ & $<.0001$ \\
\hline $2007-2008$ & $0.9(0.7-1.1)$ & & $0.8(0.5-1.2)$ & \\
\hline \multicolumn{5}{|l|}{ Activity limitation days } \\
\hline \multicolumn{5}{|c|}{ Body mass index (ref: normal weight) } \\
\hline Underweight & $1.1(0.7-1.8)$ & & $1.8(0.5-6.9)$ & \\
\hline Overweight & $1.0(0.8-1.3)$ & & $0.9(0.5-1.6)$ & \\
\hline Obese & $1.1(0.8-1.4)$ & & $1.6(0.8-3.0)$ & \\
\hline \multicolumn{5}{|l|}{ Sex (ref: girls) } \\
\hline Boys & $0.8(0.6-0.9)$ & .0035 & $0.7(0.4-1.2)$ & \\
\hline \multicolumn{5}{|l|}{ Race (ref: All other race) } \\
\hline Non-Hispanic White & $1.3(0.9-2.0)$ & & $2.8(1.0-8.0)$ & .0436 \\
\hline Non-Hispanic Black & $1.3(0.9-2.0)$ & & $3.0(1.1-8.5)$ & .0368 \\
\hline Mexican-American & $1.3(0.8-1.9)$ & & $1.3(0.5-3.9)$ & \\
\hline \multicolumn{5}{|l|}{ Age (ref: $15-17$ years old) } \\
\hline $12-14$ years old & $1.0(0.8-1.1)$ & & $1.0(0.6-1.7)$ & \\
\hline \multicolumn{5}{|c|}{ Family poverty-income ratio (ref: high-income families) } \\
\hline Low income families & $0.9(0.8-1.2)$ & & $1.0(0.5-1.9)$ & \\
\hline Middle income families & $0.9(0.8-1.2)$ & & $1.3(0.7-2.5)$ & \\
\hline \multicolumn{5}{|c|}{ Cigarette smoking (ref: current smokers) } \\
\hline Never smokers & $0.7(0.5-0.9)$ & .0085 & $0.4(0.2-0.7)$ & .0007 \\
\hline Past smokers & $0.8(0.5-1.3)$ & & $0.6(0.3-1.6)$ & \\
\hline \multicolumn{5}{|c|}{ Physical inactivity (ref: physically inactive) } \\
\hline Physically active & $1.3(0.9-1.7)$ & & $2.0(0.9-4.2)$ & \\
\hline \multicolumn{5}{|c|}{ Interview year (ref: 2009-2010) } \\
\hline 2001-2002 & $0.8(0.6-1.0)$ & & $0.6(0.3-1.2)$ & \\
\hline 2003-2004 & $0.6(0.4-0.8)$ & .0010 & $0.5(0.2-1.1)$ & \\
\hline 2005-2006 & $0.6(0.5-0.9)$ & .0038 & $0.7(0.3-1.5)$ & \\
\hline 2007-2008 & $0.7(0.5-1.0)$ & .0449 & $2.4(1.1-5.3)$ & .0229 \\
\hline
\end{tabular}

$95 \%$ CI $95 \%$ confidence intervals for odds ratios, ref reference category 